\title{
Aventura Espacial: proposta de atividade para o desenvolvimento do Pensamento Computacional*
}

\author{
Yuri da Silva Rosa ${ }^{1}$, Renata Hax Sander Reiser ${ }^{1}$, \\ Simone André da Costa Cavalheiro ${ }^{1}$, Luciana Foss ${ }^{1}$, André Rauber Du Bois ${ }^{1}$, \\ Ana Rita Mazzini ${ }^{2}$, Clause Fátima de Brum Piana ${ }^{1}$ \\ ${ }^{1}$ Centro de Desenvolvimento Tecnológico - Universidade Federal de Pelotas (UFPEL) \\ ${ }^{2}$ Instituto de Física e Matemática - Universidade Federal de Pelotas (UFPEL) \\ \{ydsrosa, reiser, simone.costa, lfoss, dubois\} @inf.ufpel.edu.br
}

\begin{abstract}
This work describes the proposal of a didactic and playful activity that aims to encourage learning and the development of strategic skills, based on Computational Thinking (CT). Organized into five tasks, the detailed description of the activity aims to motivate about the relevance of knowledge, manipulation and application of data structures in problem solving. Regarding the qualification and scope, the proposal promotes effective interaction between teachers/students of Computer Science with teachers/students of Elementary Schools, consolidating experimentation of learning methods and techniques via CT in a broad spectrum, from academic teaching to the fundamental.
\end{abstract}

Resumo. Este trabalho descreve a proposta de uma atividade didática e lúdica que visa incentivar a aprendizagem e o desenvolvimento de habilidades estratégicas, fundamentadas no Pensamento Computacional (PC). Organizada em cinco tarefas, a descrição detalhada da atividade visa motivar sobre a relevância do conhecimento, manipulação e aplicação de estruturas de dados na resolução de problemas. Quanto à qualificação e abrangência, a proposta promove efetiva interação entre docentes elou discentes da Computação com professores elou alunos de Escolas de Ensino Fundamental, consolidando experimentação de métodos e técnicas de aprendizagem via PC em largo espectro, do ensino acadêmico até o fundamental.

\section{Introdução}

A discussão sobre a inserção da Computação no Ensino Básico brasileiro vem ganhando destaque. Recentemente, um texto de referência [MEC 2021b] que normatiza sobre a Computação na Educação Básica no Brasil foi disponibilizado para consulta pública [MEC 2021a]. Este documento, embasado nas Diretrizes para Ensino de Computação na Educação Básica propostas pela Sociedade Brasileira de Computação [SBC 2021], inclui competências específicas da Computação a serem desenvolvidas tanto no Ensino Fundamental como no Ensino Médio. Para desenvolvimento de tais competências, a área é organizada em três eixos principais: Pensamento Computacional, Mundo Digital e Cultura Digital.

${ }^{*} \mathrm{O}$ presente trabalho foi realizado com apoio da Coordenação de Aperfeiçoamento de Pessoal de Nível Superior - Brasil (CAPES) - Código de Financiamento 001, do MCTIC/CNPq (Rede Sacci), da SMED/Pelotas e da PREC e PRPPG / UFPel. 
O Pensamento Computacional (PC) envolve abstrações e técnicas necessárias para a descrição e análise de informações (dados) e processos, bem como para a automação de soluções. Essas técnicas desenvolvem não somente a capacidade de construir modelos abstratos (de informação e processos) e sistematizar a solução de problemas, mas também habilidades de argumentação, análise crítica e trabalho cooperativo. Nas diretrizes, os principais conceitos do PC são organizados em três pilares principais: abstração, automação e análise. Para a introdução de tais conceitos, objetos de conhecimentos e habilidades por ano do Ensino Fundamental e para o Ensino Médio são delineados.

Concomitantemente, diversas abordagens [Guarda and Pinto 2020, Silva et al. 2020] e ações [Almeida and Junior 2020, Trindade et al. 2020, Sousa and Silva 2020] vêm sendo propostas e realizadas para o desenvolvimento do PC na Educação Básica. No entanto, considerando a aprovação da normatização da Computação da Educação Básica e a necessidade de concretização de sua implementação, diversos desafios se apresentam, como a formação profissional, a disponibilização de material didático e a definição de metodologias eficazes e adequadas de efetivação.

Em particular, atividades pertinentes ao desenvolvimento dos objetos de conhecimento e à promoção das habilidades relacionadas devem ser propostas para cada nível do Ensino Básico. Este trabalho propõe uma atividade didática e lúdica para a introdução de estruturas de dados estáticas: vetores e matrizes, bem como apresenta um tutorial de formação voltado a professores que queiram replicar a atividade em sala de aula. A atividade aborda diferentes conceitos do PC, como abstração, decomposição, avaliação (de eficiência e correção) e identificação de padrões.

Vetores e matrizes são uma importante abstração da Ciência da Computação. O seu ensino, utilizando conceitos de programação, aparece em vários trabalhos focados no ensino médio/técnico, porém utilizam linguagens de programação, como C [Kalile 2019], ferramentas mais didáticas como o Scratch [Manassés Vitorino Oliveira 2016], ou planilhas [Soman et al. 2012]. Também existem exemplos de atividades lúdicas para o ensino de vetores e de matrizes para cursos a nível de graduação, como por exemplo, o uso de caixas de ovos para a sua simulação [Berardi et al. 2018].

Mais parecidas com o trabalho abordado aqui, são as atividades lúdicas para ensino do PC apresentadas no site Computação Desplugada [Bell et al. 2015]. Por exemplo, a atividade Image Representation (representação de imagens), apesar de não abordar a indexação de valores, apresenta aos alunos intuições no uso de matrizes ao ensinar a representação de imagens através matrizes de pixels e códigos de imagem. Uma abordagem parecida utilizando matrizes foi apresentada em [Cavalheiro et al. 2016]. Similarmente, ao longo da literatura encontra-se várias atividades lúdicas para ensino do PC, que apresentam noções de uso de vetor/matriz pelo fato de representarem suas abstrações com estruturas desse tipo, como por exemplo a representação do labirinto a ser percorrido por um PAC-MAN [Jagušt et al. 2018]. Diferentemente desses trabalhos, a atividade proposta neste artigo, visa dar um conhecimento mais sólido do uso de estruturas como vetores e matrizes, explorando o uso de índices, posições e acesso a valores, oferecendo simultaneamente um tutorial para formação de professores ${ }^{1}$.

\footnotetext{
${ }^{1}$ Os planos de ensino e aulas das tarefas, bem como os vídeos do tutorial estão disponíveis em: https : //wp.ufpel.edu.br/pensamentocomputacional/.
} 
Na Seção 2, são descritos os principais conceitos do PC que fundamentaram a proposta. A Seção 3 detalha a atividade, delineando o objetivo principal, a descrição geral e uma sugestão de avaliação para cada uma das tarefas que a compõe. A Seção 4 sintetiza a metodologia de concepção e o detalhamento do tutorial de formação. A descrição de como os conceitos do PC são trabalhados na atividade são apresentados na Seção 5 e, por fim, a Seção 6 contém as considerações finais.

\section{Pensamento Computacional}

O Pensamento Computacional (PC) começa a tornar-se popular após Wing declarar em seu artigo [Wing 2006] que "O pensamento computacional é uma habilidade fundamental para todos, não apenas para cientistas da computação". Porém, a ideia de que as habilidades e conceitos relacionados ao PC podem auxiliar no processo de resolução de problemas em diferentes áreas do conhecimento não era novo [Papert 1980]. Desde então, diversos autores e grupos de trabalho têm associado um conjunto de habilidades, conceitos, ferramentas e/ou técnicas ao PC [Council 2010, ISTE and CSTA 2011b, ISTE and CSTA 2011a, Selby and Woollard 2013, Royal Society 2017, Denning and Tedre 2019]. Neste trabalho, o PC é visto como uma metodologia para resolução de problemas baseada em conceitos da Ciência da Computação. Dentre estes conceitos estão a abstração para dados e processos, decomposição, reconhecimento de padrões e avaliação.

A abstração consiste em simplificar a realidade para focar nos aspectos mais relevantes do problema e ignorar os demais, permitindo assim lidar com problemas complexos. Segundo Ribeiro e outros [Ribeiro et al. 2017], a abstração compreende diferentes aspectos: abstrações para dados, como vetores e matrizes, que permitem descrever as informações envolvidas no problema; abstrações para processos, como instruções básicas e operações de combinação destas instruções, que permitem descrever as soluções dos problemas (algoritmos) e que devem ser entendidas pelo leitor. Já a decomposição é uma técnica para resolução de problemas que consiste em dividir um problema em partes menores, solucionar cada parte e combinar essas soluções para resolver o problema original. Essa técnica permite que se consiga resolver problemas mais complexos de forma mais simples [Ribeiro et al. 2017]. O reconhecimento de padrões é um processo de identificação de semelhanças compartilhadas por diferentes problemas, tanto nas informações quanto nas estratégias de resolução [Csizmadia et al. 2015]. Essa identificação permite reformular soluções para que possam resolver uma classe de problemas semelhantes. Por sua vez, a avaliação é o processo de garantir que uma solução seja adequada ao seu propósito [Csizmadia et al. 2015]. Este processo pode levar em conta diferentes aspectos como: correção, quando se analisa se a solução resolve de fato o problema envolvido; eficiência, quando se analisa se a solução é eficiente sob diferentes aspectos (tempo de resolução, espaço de memória utilizado, energia necessária para execução, etc); e viabilidade, quando se analisa a existência de uma solução computacional para o problema [Ribeiro et al. 2017].

\section{Atividade Aventura Espacial}

A atividade Aventura Espacial promove o uso de conceitos e habilidades do PC, trabalhando em especial com os conceitos de estrutura de dados homogêneos e estáticos, como vetores e matrizes. Esta atividade foi desenvolvida para estudantes do $4^{\mathbf{O}}$ ano do Ensino 
Fundamental e está contextualizada em uma história sobre viagens espaciais da personagem Alex, uma cientista e astronauta que precisa de amostras de rochas encontradas em todo o sistema solar. A atividade está dividida em 5 tarefas de duração média entre 50 à 100 minutos, considerando o checklist (Figura 1) e o mapa do Sistema Solar (Figura 2), os quais constituem os principais instrumentos que acompanham os estudantes durante toda aplicação da atividade. O checklist será usado como guia de tarefas a serem cumpridas até o momento da Tarefa 5 que é um jogo. O mapa do sistema solar apresenta todos os planetas dispostos sobre uma grade. Os quadrados grifados, cobertos pelos planetas, marcam suas atmosferas. Já os traços brancos na borda destas atmosferas é o local de chegada e saída da nave, sendo que a nave não aterrissa no planeta, apenas fica em sua órbita.

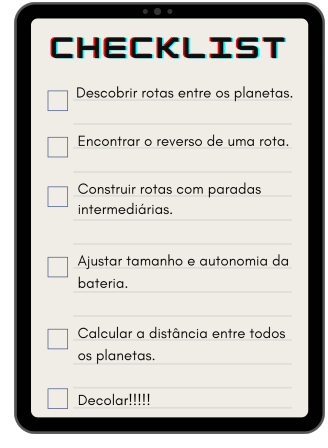

Figura 1. Checklist.

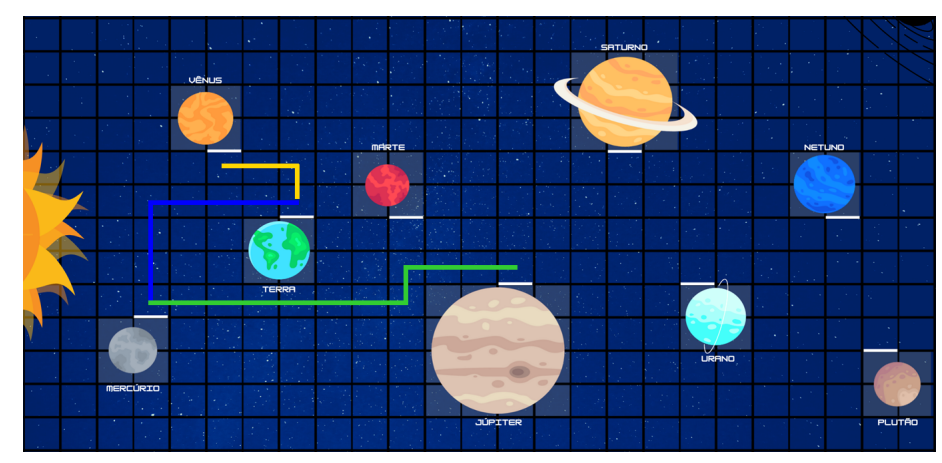

Figura 2. Mapa do Sistema Solar.

\subsection{Tarefa 1}

Objetivo: estimular os alunos a perceberem a importância dos conceitos (comprimento, posições, índices e valores) de vetores, na modelagem de rotas que viabilizam as viagens exploratórias de Alex na Aventura Espacial. E, ainda, identificar e representar origem, destino e valores (símbolos de navegação) associados à modelagem de rotas.

Descrição: após realizar uma introdução sobre a personagem Alex e sua viagem no sistema solar em busca de pedras de valor científico, introduz-se a noção de vetor na representação de rotas entre planetas do sistema solar, identificando suas origens e destinos. Assim, cada rota é caracterizada por um vetor com posições que variam desde 1 até o número que define seu comprimento. Cada posição é preenchida por símbolos de navegação que consistem em setas direcionais, para cima, para baixo, para esquerda e para direita. Estes símbolos indicam os movimentos que a nave terá que realizar para sair de um planeta e chegar em outro. Na sequência da tarefa, a rota selecionada entre dois planetas é marcada no mapa do Sistema Solar, considerando apenas linhas verticais e horizontais, sem usar as diagonais. Após o traçado da rota, os quadrados marcados pela rota da nave serão computados, determinando assim o tamanho da rota e o tamanho do vetor de rota. Logo após, os alunos são estimulados a preencher as posições com os símbolos de navegação, de forma que representem os movimentos da nave de Alex. Alguns exemplos de construção de rotas são realizados com a turma, introduzindo aqui a importância de se encontrar a menor rota entre dois planetas. O primeiro item do checklist, referente à execução da Tarefa 1 é marcado, como concluído.

Avaliação: ao final da tarefa, propõem-se exercícios sobre a construção de rotas, trabalhando os conceitos de tamanho e índices dos vetores, bem como a construção de sequências de passos para construir rotas (preferencialmente com o menor tamanho possível). 


\subsection{Tarefa 2}

Objetivo: introduzir o conceito de concatenação de vetores e operação de reversibilidade, viabilizando a construção de rotas com paradas intermediarias e de rota reversa, respectivamente, as quais serão usadas para novas investigações de Alex na Aventura Espacial.

Descrição: primeiramente, tem-se uma breve retomada da tarefa anterior com perguntas aos alunos, ajudando a lembrar rapidamente os conceitos já explorados. Evitam-se resposta diretas e, estimula-se a turma a buscar as respostas corretas. Na descoberta do reverso de uma rota, tem-se duas etapas:

(1) Cria-se um novo vetor pela permutação de índices com mesmo tamanho do vetor original da rota já alcançada. Nesta etapa, preservam-se os valores de cada índice na permutação reversa das posições do vetor em relação ao original. Ou seja, o valor da última posição vai para a primeira posição, e vice-versa, e o mesmo com as demais posições equidistantes da posição central. O processo de troca continuará até permutar, na ordem reversa, todas as posições do vetor conservando seus correspondentes valores. Para vetores com número ímpar de comprimento, o valor da posição central não se altera.

(2) Usando uma tabela de símbolos invertidos, invertem-se os valores das posições do vetor reverso, isto é, se há um símbolo de navegação para cima, troca-se pelo símbolo de navegação para baixo, se há um símbolo para a direita, troca-se pelo símbolo para a esquerda, e assim por diante até todos serem invertidos.

Assim, obtém-se o vetor reverso que modela o retorno da nave de Alex, do planeta onde está atualmente para o planeta onde estava anteriormente.

Na sequência, nesta mesma tarefa, propõe-se a construção de rotas com paradas intermediárias que viabilizam a investigação de pedras em mais de um planeta, antes de finalizar uma das viagens de Alex. Como condição, para as rotas selecionadas para a composição, tem-se que o destino de uma deve coincidir com a origem da outra. A Figura 2 exemplifica a composição de duas rotas, uma que vai de Mercúrio para Terra (rota azul), e outra que vai da Terra a Vênus (rota amarela), resultando numa viagem com rota de Mercúrio até Vênus, passando pela Terra. O novo vetor, modelando a composição de duas rotas, tem dimensão igual a soma das dimensões dos outros dois vetores e contém, como valores das posições, todos os símbolos de navegação, na mesma ordem, já usados nas duas rotas. Marca-se então o item sobre vetor reverso e composição de rotas no checklist.

Avaliação: ao final da tarefa, propõe-se uma listagem de exercícios de fixação sobre reversão e composição de rotas.

\subsection{Tarefa 3}

Objetivo: comparar o comprimento e valores dos vetores de bateria e de rota, viabilizando o ajuste de baterias e autonomia da nave na seleção de rotas e controle de energia, para suporte às investigações de Alex na Aventura Espacial.

Descrição: nesta tarefa trabalha-se a comparação entre comprimento e valores de vetores, modelando a capacidade de carga da bateria que provê energia para as viagens da nave de Alex. Caracterizam-se os ajustes da bateria e a autonomia da nave durante a execução de uma rota. Neste contexto, se a nave suporta apenas uma bateria de tamanho 10, temse sua representação dada por um vetor de comprimento 10, associando a cada uma das posições deste vetor de bateria os valores 0 (para sem carga de energia) ou 1 (com carga de energia). A comparação entre vetores que descrevem a rota e o consumo de energia viabiliza a plena realização das viagens de Alex, que precisa sempre verificar se há energia 
suficiente na bateria para completar a viagem planejada. Para cada movimento que a nave necessita realizar na rota selecionada, será alterado de 1 para 0 o valor da correspondente posição do vetor da bateria. Assim, a cada trecho percorrido em uma viagem, ocorre a atualização do vetor de bateria, informando que a energia na posição correspondente foi consumida na execução do movimento da nave. Caso não haja energia suficiente no vetor de bateria, a rota não poderá ser executada, pois a nave corre o risco de ficar perdida no espaço. No mapa da Figura 2, há três exemplos de rotas, uma rota entre Mercúrio e a Terra, de comprimento 7, outra de Mercúrio a Júpiter, de comprimento 11, e a rota entre a Terra e Vênus, com comprimento 3. Considerando-se um vetor de bateria com tamanho 10, verifica-se, facilmente que a nave não consegue sair de Mercúrio e chegar a Júpiter antes da bateria estar completamente zerada. Logo, esta viagem é inviável. No caso de uma viagem da Terra a Vênus, podemos ver que a rota é concluída e ainda sobra de carga na bateria. Pode-se, inclusive, propor a rota reversa, e ainda sobrará energia. Com isso, marca-se como concluído o item de ajuste de tamanho e autonomia de energia da nave no checklist.

Avaliação: ao final da tarefa, propõe-se uma listagem de exercícios para exercitar sobre o ajuste de carga e comprimento de rotas.

\subsection{Tarefa 4}

Objetivo: usar matrizes, estruturas de dados bidimensionais, na modelagem dos relatórios da Alex sobre distâncias entre os planetas e a coleta de amostras de pedras, dando suporte ao planejamento e realização da viagem da Aventura Espacial.

Descrição: consideram-se duas estruturas matriciais, permitindo a consulta e a armazenagem de informação sobre distâncias entre planetas e amostras coletadas nas rotas percorridas, respectivamente. A primeira tabulação correlaciona as (menores) distâncias entre todos os planetas, sendo modelada por uma matriz quadrada de ordem 9 (visto que são nove os planetas do Sistema Solar), denominada de Distâncias-entre-Planetas ([DP]). As entradas identificando as linhas e colunas desta matriz contém os nomes dos planetas e os valores associados aos pares de índices $(i, j)$ (intersecção da $i$-linha com $j$-coluna) correspondem à (menor) distância entre os dois planetas identificados na linha e coluna consideradas. A Tabela 1 ilustra a matriz [DP] parcialmente preenchida. Nesta matriz pode-se observar que as distâncias: (a) Mercúrio $\times$ Terra - descrita na posição $(1,3)$ é de 7 unidades (de forma simétrica a distância Terra $\times$ Mercúrio - posição $(3,1)$ - é a mesma); (b) Mercúrio $\times$ Mercúrio - definida na posição $(1,1)$ - é de 0 (zero) unidades, assim como todos os valores da diagonal principal que representam a distância de cada planeta de si próprio. Desta forma, se a nave comandada por Alex está em Mercúrio, com nível de carga de energia igual a 7, ao olhar as células da linha 1 da matriz [DP], pode-se saber quais são as possíveis viagens a serem agendadas antes de novos abastecimentos, isto é, todas com distância menor ou igual a 7. A segunda tabulação, modelada por uma matriz denominada Pedras-coletadas-Planeta ([PP]), correlaciona o número de pedras de um determinado tipo encontradas em um planeta. A matriz [PP] é usada como abstração para uma caixa com compartimentos onde são armazenadas as amostras encontradas em cada planeta, tendo assim como entrada das linhas a identificação do tipo de pedra e das colunas os planetas do Sistema Solar. O valor associado a uma posição $(i, j)$ corresponde à quantidade de amostras de pedras do tipo $i$ encontradas no planeta $j$. Nesta tarefa, também será disponibilizado aos alunos um conjunto de cartas com características de cada planeta, onde estão registados dados (tipo e a quantidade) de amostras de pedras e/ou 
bônus de energia. Desta forma, ao visitar um planeta, a equipe escolherá uma carta que definirá as amostras coletadas e a energia recebida com a visita. Ao iniciar a aventura, a matriz [PP] possui todos os seus valores zerados, que são atualizados a cada carta selecionada. A atualização se dá com a soma do novo valor (da carta) ao valor que já está registrado (em [PP]) para aquele tipo de pedra no correspondente planeta. A Tabela 2 ilustra uma possível instância da matriz [PP], onde nota-se que já foram coletadas, em Mercúrio, 2 pedras do tipo Gipsita e 1 pedra do tipo Fluorita. Neste caso, se Alex visitar novamente o planeta Mercúrio e for selecionada uma carta indicando que foram encontradas 3 pedras do tipo Gipsita, a posição $(1,1)$ da matriz [PP] terá seu valor atualizado para 5. Após o preenchimento de algumas células da tabela [DP] e a realização de algumas viagens para se compreender a mecânica de coleta das amostras, marca-se como concluído, no checklist, o item relacionado ao cálculo das distâncias.

Avaliação: para concluir a tarefa, os alunos devem completar o preenchimento da matriz [DP].

Tabela 1. [DP]: Distância $\times$ Planetas.

\begin{tabular}{|c|c|c|c|c|c|c|c|c|}
\hline & $\mathrm{Me}$ & $\mathrm{V}$ & $\mathrm{T}$ & $|\mathrm{Ma}| \mathrm{J}$ & $\mathrm{S}$ & $\mathrm{N}$ & & $P$ \\
\hline $\mathrm{Me}$ & 0 & & 7 & | & & & & | \\
\hline $\mathrm{V}$ & & 0 & 3 & | 1 & & & & 1 \\
\hline $\mathrm{T}$ & 7 & 3 & $\mid 0$ & $\mid$ & & & & 1 \\
\hline $\mathrm{Ma}$ & & & & $|0|$ & & & & 1 \\
\hline $\mathrm{J}$ & & & & 110 & & & & 1 \\
\hline $\mathrm{S}$ & & & & 11 & 0 & & & 1 \\
\hline $\mathrm{U}$ & & & & 11 & & 0 & & | \\
\hline $\mathrm{N}$ & & & & 11 & & & 0 & \\
\hline $\mathrm{P}$ & & & & 1 & & 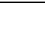 & & 10 \\
\hline
\end{tabular}

Tabela 2. [PP]: Pedras $\times$ Planetas.

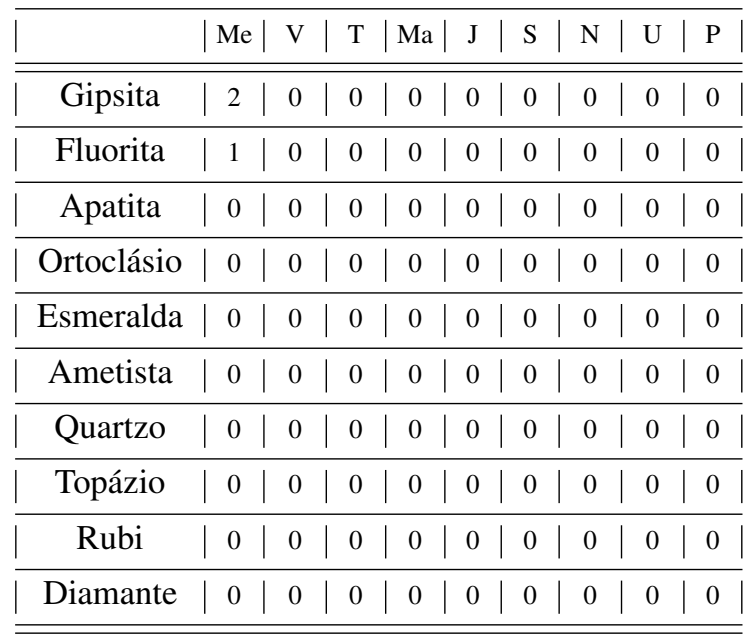

\subsection{Tarefa 5}

Objetivo: promover a realização da Aventura Espacial, apresentando, inicialmente, as funções dos componentes e as regras gerais do jogo.

Descrição: apresentam-se as últimas regras do jogo e estruturam-se as equipes para a realização da tarefa. As equipes são compostas por 6 integrantes, com os seguintes papeis: 2 capitães, 2 engenheiros da nave, 1 explorador e 1 tesoureiro, cada um com uma função específica. Fazendo uso do mapa e da matriz [DP], os capitães devem prover à tripulação três rotas de navegação para distintos prováveis destinos, incluindo a especificação dos 3 vetores de rotas. A partida de todas as rotas deve ser do planeta Terra e elas devem prever o retorno à origem. O primeiro destino será o mais votado pelos demais componentes da equipe. Após seleção da rota, os engenheiros da nave são responsáveis por dimensionar as baterias e monitorar o nível de energia durante a viagem, atualizando o vetor de bateria. Ao chegar em algum planeta, o explorador deverá escolher uma carta do monte de cartas referentes àquele planeta e, em seguida, apresentar as informações aos demais tripulantes. Esta carta irá informar a quantidade e o tipo de amostras encontradas e, possivelmente, algum bônus de energia. Considerando essas informações, o tesoureiro atualiza a matriz 
de amostras [PP] e os engenheiros atualizam o vetor de bateria, no caso de haver algum bônus. Ao concluir a primeira viagem, é escolhida por votação a próxima rota. A aventura segue assim até que a equipe tenha encontrado ao menos uma amostra de cada tipo de rocha. Com a finalização desta tarefa, marcam-se como concluído, no checklist, o item que descreve o início das viagens, isto é, o item "Decolar".

Avaliação: se dá através da realização e observação de diversas partidas do jogo.

\section{Descrição do Tutorial de Formação}

É cada vez mais frequente que os primeiros contatos com a Ciência da Computação, seja por alunos ou por profissionais de ensino, ocorram por meio de atividades online. Por isto, é fundamental que tutoriais sejam bem fundamentados e planejados de forma que seja possível manter o equilíbrio entre o envolvimento, a motivação e a aprendizagem [Gohl 2016].

Tutoriais que fornecem muitas informações podem acabar se tornando cansativos de serem seguidos. Neste caso, mesmo que os usuários consigam compreender todas as informações, podem acabar se sentindo entediados. Por outro lado, tutoriais que não fornecem detalhes suficientes podem levar o usuário a frustração, podendo conduzir a desistência do processo de formação.

O tutorial proposto nesta seção apresenta a atividade Aventura-Espacial descrito na seção 3. Uma vez que o tutorial é voltado a professores da Educação Básica que possivelmente não conhecem os conceitos de vetores e matrizes, e objetivam replicar a atividade em sala de aula, buscou-se um equilíbrio entre a apresentação dos conceitos e a proposta de desenvolvimento lúdico em sala de aula.

A metodologia de desenvolvimento do tutorial compreendeu as seguintes etapas:

- Apresentação dos fundamentos: identificou-se todos os conceitos que seriam apresentados e, seguindo a temática da viagem espacial proposta na concepção da atividade, criou-se uma sequência que permitisse apresentar todos os conceitos dentro da mesma temática.

- Abordagem metodológica: foi estabelecido que a introdução dos conceitos seria incremental e "em espiral", de forma que os tópicos apresentados em um vídeo fossem revisitados nos vídeos subsequentes.

- Indicação de exercícios de fixação: optou-se por restringir o tutorial a apresentação e exemplificação dos conceitos e por apenas indicar os exercícios de fixação ao final das apresentações. Isto reduz o tempo do vídeo. Em caso de dúvidas, são disponibilizadas formas de contato com a equipe do projeto.

- Estruturação da proposta: optou-se por organizar o tutorial em pequenos vídeos autocontidos, permitindo que o usuário pudesse fazer o curso em intervalos de tempo intercalados. Para cada tarefa, foi desenvolvido uma videoaula de curta duração contendo a descrição do seu objetivo, a metodologia de desenvolvimento e a indicação de exercícios de fixação.

Na Tabela 3, destaca-se para cada vídeo o detalhamento dos aspectos considerados. 
Tabela 3. Detalhamento dos vídeos do tutorial.

\begin{tabular}{|c|c|c|c|}
\hline Vídeo & $\begin{array}{l}\text { Delimitação dos } \\
\text { fundamentos }\end{array}$ & Abordagem metodológica & $\begin{array}{l}\text { Seleção de exercícios de } \\
\text { fixação }\end{array}$ \\
\hline 1 & $\begin{array}{l}\text { Introduz o conceito de } \\
\text { vetor, abordando } \\
\text { dimensão, posições e } \\
\text { valores armazenados. }\end{array}$ & $\begin{array}{l}\text { Ilustra a apresentação dos conceitos traçando uma rota entre } \\
\text { dois planetas, Mercúrio e Terra. Apresenta-se dimensão } \\
\text { definindo a distância entre os planetas, os valores } \\
\text { armazenados por símbolos que estabelecem o sentido do } \\
\text { movimento que as naves devem realizar para percorrer uma } \\
\text { rota e as posições para indicar a sequência de } \\
\text { movimentações a serem seguidas. }\end{array}$ & $\begin{array}{l}\text { São indicados exercícios } \\
\text { que dão ênfase à } \\
\text { comparação entre vetores } \\
\text { de diferentes dimensões, à } \\
\text { relação entre posição e } \\
\text { valor e à representação e } \\
\text { uso das estruturas } \\
\text { apresentadas. }\end{array}$ \\
\hline 2 & $\begin{array}{l}\text { Apresenta o conceito } \\
\text { de rota reversa, } \\
\text { representada em um } \\
\text { vetor e a construção de } \\
\text { rotas com paradas } \\
\text { intermediárias, } \\
\text { realizada a partir da } \\
\text { criação de um vetor que } \\
\text { representa a } \\
\text { composição de rotas. }\end{array}$ & $\begin{array}{l}\text { Indica-se passo a passo como determinar o reverso de uma } \\
\text { rota, que corresponde ao caminho de volta da rota original. } \\
\text { Para a construção de rotas com paradas intermediárias, } \\
\text { define-se uma rota de viagem de Mercúrio a Vênus com } \\
\text { uma parada intermediária na Terra. }\end{array}$ & - \\
\hline 3 & $\begin{array}{l}\text { Aborda a comparação } \\
\text { de vetores. }\end{array}$ & $\begin{array}{l}\text { Acrescenta-se a informação sobre as baterias das naves, de } \\
\text { forma que uma rota só pode ser realizada, quando a nave } \\
\text { possui bateria suficiente. A informação sobre a bateria é } \\
\text { armazenada em um vetor de dimensão } 10 \text {, o qual armazena } \\
\text { valores binários ( } 1 \text { indicando carga de energia e } 0 \text { indicando } \\
\text { ausência de carga, em uma dada posição). Para que uma } \\
\text { rota seja percorrida, primeiro deve ser verificada a } \\
\text { existência de carga suficiente, por meio da comparação } \\
\text { entre os vetores de rota e de bateria. }\end{array}$ & $\begin{array}{l}\text { Os exercícios abordam a } \\
\text { definição de rotas e } \\
\text { análise de carga de bateria } \\
\text { suficiente para completar } \\
\text { as respectivas rotas, } \\
\text { indicando a viabilidade } \\
\text { das viagens. }\end{array}$ \\
\hline 4 & $\begin{array}{l}\text { Introduz o conceito de } \\
\text { matriz. }\end{array}$ & $\begin{array}{l}\text { Matrizes são utilizadas para armazenar a distância entre os } \\
\text { planetas da galáxia e para indicar amostras de pedras } \\
\text { encontradas nos planetas. }\end{array}$ & $\begin{array}{l}\text { Após o preenchimento de } \\
\text { uma matriz de distância } \\
\text { entre os planetas, o qual } \\
\text { servirá de consulta para a } \\
\text { resolução das demais } \\
\text { questões, são abordadas } \\
\text { questões que envolvem a } \\
\text { revisão de conceitos } \\
\text { anteriores, como a } \\
\text { definição e comparação de } \\
\text { rotas (envolvendo } \\
\text { dimensões de vetores) e } \\
\text { rota reversa. }\end{array}$ \\
\hline 5 & $\begin{array}{l}\text { Revisão dos conceitos } \\
\text { apresentados. }\end{array}$ & $\begin{array}{l}\text { Apresentação do jogo interplanetário que aborda todos os } \\
\text { conceitos estudados. }\end{array}$ & - \\
\hline
\end{tabular}

\section{Conceitos do Pensamento Computacional na atividade Aventura Espacial}

A atividade proposta neste trabalho aborda diferentes conceitos do PC em cada uma de suas tarefas. A estrutura de vetor foi utilizada como abstração para representação de caminhos no mapa e as setas direcionais são as instruções básicas usadas para representação do algoritmo que determina as manobras que a espaçonave deve realizar para sair de um planeta e chegar em outro. Além disso, também se usou vetores como abstração para representar a informação sobre o nível de energia da espaçonave. As operações de concatenação e construção de vetor reverso são operações que representam situações concretas que ocorrem na aventura: viagens mais longas formadas por vários trechos menores e viagens de retorno ao planeta de origem, respectivamente. Essas operações são também abstrações para processos. Outras estruturas usadas como abstração para representação de informações foram as matrizes. O próprio mapa do sistema solar é uma abstração da realidade, no qual usa-se uma grade (matriz) para representar as unidades de distâncias entre os planetas e os possíveis "passos" de uma rota. Já as matrizes de distância e amostras 
coletadas são usadas para representar relações entre algumas das informações envolvidas no problema de planejar uma viagem espacial, sendo a última a abstração de uma caixa com diversos compartimentos.

A decomposição foi aplicada na construção das rotas, principalmente das rotas com paradas intermediárias. Aqui, uma rota é dividida em trechos de acordo com a quantidade de combustível disponível na nave. Depois, para cada trecho, é descrita uma sequência de instruções para navegar até o planeta intermediário. E, finalmente, a concatenação dos vetores de navegação de todos os trechos resultam no vetor de navegação da rota completa. Ao construir as rotas entre dois planetas, os alunos devem se preocupar com a quantidade de energia disponível na nave e tentar traçar a menor rota possível para economizar combustível. Esta checagem caracteriza a avaliação de eficiência. Além disso, a avaliação de correção também é feita: ao construir os vetores de navegação, os alunos devem testar para saber se de fato a sequência de instruções leva de fato do planeta de origem ao de destino. Na busca pela menor rota entre dois planetas, os alunos são orientados a identificar padrões nos vetores de navegação. As menores rotas não devem usar símbolos inversos, ou seja, se uma rota usa uma seta para cima, não podem aparecer setas para baixo, e vice-versa (de forma análoga, se usar uma seta para à esquerda, não podem aparecer setas para à direita, e vice-versa).

Desta forma, os diferentes conceitos do PC são abordados no decorrer da atividade como uma forma de viabilizar ou melhorar as viagens espaciais tornando-os essenciais para a Aventura Espacial.

\section{Conclusão}

Na atividade didática e lúdica Aventura Espacial, os conceitos de estrutura de dados homogêneos e estáticos de vetores e matrizes foram considerados para modelagem de rotas e mapas exploratórios. Além destes, foram trabalhadas as relações entre posições e valores destas estruturas de dados, identificando métricas para análise e ajustes de direção, carga e consumo da nave de navegação da personagem Alex, bem como comprimento entre rotas percorridas no mapa do Sistema Solar. A consolidação da atividade prevê a execução do jogo por grupos de alunos com seleção de atribuições para execução das jogadas. A avaliação passa pela resolução de exercícios, cuja complexidade é apresentada de forma incremental de acordo com a sequência das atividades desenvolvidas.

Como trabalhos futuros, pretende-se aplicar a atividade em turmas de ensino fundamental, bem como analisar o seu potencial de integração com os pressupostos teóricopedagógicos do quarto ano do Ensino Fundamental.

\section{Referências}

Almeida, W. D. and Junior, A. C. (2020). A aplicação de uma sequência didática no processo de desenvolvimento do pensamento computacional com alunos do $4^{\circ}$ ano do ensino fundamental i. In Anais do XXVI Workshop de Informática na Escola, pages 11-20, Porto Alegre, RS, Brasil. SBC.

Bell, T., Witten, I. H., and Fellows, M. (2015). Computer Science Unplugged: an enrichment and extension programme for primary-aged students. 
Berardi, R. C. G., Bim, S. A., Macuch, R., and Forno, L. F. D. (2018). Experiência de uso de caixas de ovos no apoio ao ensino de vetores e matrizes. In Anais do XXVI Workshop sobre Educação em Computação. SBC.

Cavalheiro, S., Pernas, A., de Aguiar, M., Foss, L., Bois, A. D., Reiser, R., Piana, C., and Weisshahn, Y. (2016). Information organization via computational thinking: case study in a primary school classroom. In Anais do XXIV Workshop sobre Educação em Computação, pages 181-190, Porto Alegre, RS, Brasil. SBC.

Council, N. R. (2010). Report of a Workshop on the Scope and Nature of Computational Thinking. The National Academies Press, Washington, DC.

Csizmadia, A., Curzon, P., Dorling, M., Humphreys, S., Ng, T., Selby, C., and Woollard, J. (2015). Computational thinking-A guide for teachers. Computing At School. Disponível em https://community.computingatschool.org. uk/resources/2324/single. Acesso em: julho de 2021.

Denning, P. J. and Tedre, M. (2019). Computational Thinking. MIT Press.

Gohl, L. (2016). Usability guidelines for the creation and evaluation of functional and engaging tutorials in computer games. $\mathrm{PhD}$ thesis, Universidade da Europa para $\mathrm{Ci}-$ ências Aplicadas, Alemanha.

Guarda, G. and Pinto, S. (2020). Dimensões do pensamento computacional: conceitos, práticas e novas perspectivas. In Anais do XXXI Simpósio Brasileiro de Informática na Educação, pages 1463-1472, Porto Alegre, RS, Brasil. SBC.

ISTE and CSTA (2011a). Computational thinking in K-12 education: leadership toolkit. Disponivel em https://cdn.iste.org/www-root/2020-10/ISTE_ CT_Leadership_Toolkit_booklet.pdf. Acesso em: julho de 2021.

ISTE and CSTA (2011b). Operational definition of computational thinking. Disponível em https://cdn.iste.org/www-root/Computational_Thinking_ Operational_Definition_ISTE.pdf. Acesso em: julho de 2021.

Jagušt, T., Krzic, A. S., Gledec, G., Grgić, M., and Bojic, I. (2018). Exploring different unplugged game-like activities for teaching computational thinking. In 2018 IEEE Frontiers in Education Conference (FIE), pages 1-5. IEEE.

Kalile, P. A. (2019). Programação como uma ferramenta no ensino de matrizes. In XXIII Encontro Brasileiro de Estudantes de Pós-Graduação em Educação Matemática. UNICSUL.

Manassés Vitorino Oliveira, Luciene Cavalcanti Rodrigues, A. Q. (2016). Material didático lúdico: uso da ferramenta scratch para auxílio no aprendizado de lógica da programação. In Anais do XXII Workshop de Informática na Escola (WIE 2016). SBC.

MEC (2021a). EDITAL DE CHAMAMENTO - Normas sobre Computação na Educação Básica - Complemento à BNCC. http: //portal.mec.gov.br/conselho-nacional-de-educacao/ audiencias-e-consultas-publicas.

MEC (2021b). Normas sobre Computação na Educação Básica - Complemento à BNCC. http://portal.mec.gov.br/conselho-nacional-de-educacao/ audiencias-e-consultas-publicas. 
Papert, S. (1980). Mindstorms: Children, computers, and powerful ideas. Basic Books.

Ribeiro, L., Foss, L., and da Costa Cavalheiro, S. A. (2017). Entendendo o pensamento computacional. Disponível em https://arxiv.org/pdf/1707.00338.pdf. Acesso em: julho de 2021.

Royal Society (2017). After the reboot: computing education in uk schools. Disponível em https://royalsociety.org/ /media/policy/projects/ computing-education/computing-education-report.pdf. Acesso em: julho de 2021.

SBC (2021). Diretrizes para ensino de Computação na Educação Básica. Disponível em https://www.sbc.org.br/ documentos-da-sbc/summary/203-educacao-basica/ 1220-bncc-em-itinerario-informativo-computacao-2. Acesso em: Julho de 2021.

Selby, C. and Woollard, J. (2013). Computational thinking: the developing definition. Project report, University of Southampton.

Silva, E., Silva, J., and Farias, C. (2020). Robótica pedagógica no exercício do pensamento computacional. In Anais do XXVI Workshop de Informática na Escola, pages 51-60, Porto Alegre, RS, Brasil. SBC.

Soman, K., V.G, M. U., Krishnan, P., and Sowmya, V. (2012). Enhancing computational thinking with spreadsheet and fractal geometry: Part 1. International Journal of Computer Applications, 55(14):1-8.

Sousa, H. and Silva, M. (2020). Run marco e o pensamento computacional: possibilidades para a educação infantil. In Anais do XXVI Workshop de Informática na Escola, pages 239-248, Porto Alegre, RS, Brasil. SBC.

Trindade, G., Fernandes, F., Barbosa, L. S., and de Souza, D. (2020). O uso do jogo digital minecraft para estimular o pensamento computacional e a aprendizagem colaborativa no ensino fundamental i: Um relato de experiência. In Anais do XXVI Workshop de Informática na Escola, pages 219-228, Porto Alegre, RS, Brasil. SBC.

Wing, J. M. (2006). Computational thinking. Communications of the ACM, 49(3):33-35. 